\title{
Psicologia Escolar no Brasil e no Maranhão: percursos históricos e tendências atuais
}

\author{
Tatiana Oliveira de Carvalho \\ Claisy Maria Marinho-Araujo
}

\begin{abstract}
Resumo
Discute-se o cenário atual da Psicologia Escolar no Maranhão, tendo como parâmetro as transformações ocorridas nas últimas décadas em âmbito nacional. Foi realizado um estudo bibliográfico sobre o tema, a partir do qual se levantaram reflexões sobre o histórico e as tendências atuais no âmbito da formação e atuação do psicólogo escolar no estado. Considera-se que no Maranhão necessita-se da contribuição de psicólogos escolares que, seguros de seu papel e intencionalidade, construam uma identidade profissional comprometida com as transformações sociais do contexto local, o que começa a se efetivar através do aprimoramento da formação na área.
\end{abstract}

Palavras-chave: Psicologia Escolar, formação do psicólogo, atuação do psicólogo.

\section{School Psychology in Brazil and in the State of Maranhão: history and current trends}

\begin{abstract}
This paper presents a discussion on the current scenario in School Psychology in the State of Maranhão. We use, as parameter, the transformations that occurred throughout the country in the last decades. . A bibliographic study on the subject has been carried out and used for later reflections about the history and current trends regarding the training and work of school psychologists in the State of Maranhão. We concluded that Maranhão needs the contribution of school psychologists who are certain of their role and intentions so they can build their professional identity with commitment to local social transformations, which starts with the improvement of expertise in the area.
\end{abstract}

Keywords: School Psychology, psychologist performance, psychologist education.

\section{Psicología escolar en Brasil y en Maranhão: Recorridos históricos y tendencias}

\begin{abstract}
Resumen
Se discute el escenario actual de la Psicología Escolar en el estado de Maranhão, usando como parámetro las transformaciones de las últimas décadas en el ámbito nacional. Fue realizado un estudio bibliográfico sobre el tema, a partir del cual se levantaron reflexiones sobre la historia y las tendencias actuales en el ámbito de la formación y actuación del psicólogo escolar en el estado. Se considera que en Maranhão es necesaria la contribución de psicólogos escolares que, seguros de su papel e intencionalidad, construyan una identidad profesional comprometida con las transformaciones sociales del contexto local, lo que comienza a hacerse efectivo a través del perfeccionamiento de la formación en el área.
\end{abstract}

Palabras-clave: Psicología escolar, formación del psicólogo, actuación del psicólogo. 
APsicologia se difunde no Brasil, na transição do século XIX para o século XX, como campo de estudos e pesquisas da Medicina e da Pedagogia. Ao longo deste último século, viu-se surgir e crescer a demanda por profissionalização e capacitação na área. Na década de 50 , surgiu a graduação em Psicologia e, na década seguinte, a regulamentação da profissão de psicólogo, com a consolidação da Psicologia Escolar como uma das áreas de atuação deste profissional.

Apesar de sua história recente, a Psicologia no Brasil tem sido marcada por mudanças paradigmáticas que refletem a tentativa de rompimento com os padrões tradicionais da teoria e da prática psicológica. Desde seus primórdios, a Psicologia brasileira esteve articulada à Educação, de forma que a história da Psicologia Escolar tem acompanhado esse movimento de mudança em direção a novos referenciais teórico-práticos. Compreende-se, atualmente, que a Psicologia Escolar não é uma mera área de aplicação da Psicologia, mas um campo de produção de conhecimentos, de pesquisa e de intervenção (Araujo, 2003).

O paradigma positivista, sobre o qual a Psicologia científica nasceu há pouco mais de um século, definiu um padrão de ciência psicológica que fora adotado pelo Brasil e transposto para a prática educativa em forma de um modelo clínico e acrítico de intervenção na escola (Antunes, 2003; Campos \& Jucá, 2003; D. B. de Carvalho, 2004). O foco principal da Psicologia articulada à Educação, nessa perspectiva, era o atendimento a dificuldades de aprendizagem dos alunos, culpabilizados por seu fracasso, cuja análise era feita com a utilização descontextualizada e estigmatizadora de testes psicológicos. Dentre as primeiras formas de aplicação da Psicologia no Brasil, em seu diálogo com o campo educativo, surgia também a Orientação Profissional, com o mesmo instrumental metodológico limitado à utilização de testes ((D. B. de Carvalho, 2004).

As décadas de 70 e 80 assistiram à emergência de duras críticas a essa forma de ação da Psicologia na Educação. Bock (1999) analisa que, especialmente a partir da década de 80 , diante das condições de vida tão deterioradas do povo brasileiro, geradoras de sofrimento psíquico, os psicólogos já não puderam mais manter-se de costas para esta realidade. Rompendo com a tradição individualista, naturalizante e patologizante da ciência e da prática psicológicas, começou a surgir uma nova Psicologia, que está se transformando para atender à exigência de compromisso social. Cada vez mais amplamente aceito pela categoria como critério de qualidade da intervenção psicológica, tal compromisso se expressa através da postura crítica do profissional perante a realidade de seu contexto de atuação e de atitudes condizentes à busca da transformação das condições de vida das pessoas com as quais trabalha.

A Psicologia Escolar brasileira, nos últimos anos, tem também buscado responder a esse apelo. No início da década de 90, ainda marcado por uma grande inquietação da psicologia brasileira com questões relacionadas a sua identidade e seu compromisso social, instituiu-se o Grupo de Trabalho de Psicologia Escolar/Educacional da Associação Nacional de Pesquisa e Pós-Graduação em Psicologia
- ANPEPP. Os trabalhos deste grupo, que mantém representações de vários estados, vêm possibilitando um grande salto no que diz respeito à ampliação da leitura da realidade nacional relativa à área da Psicologia Escolar. Exemplo disso é o livro Psicologia Escolar: Compromisso Social (Martínez, 2005a), que espelha as reflexões e debates que vêm sendo desenvolvidos pelo grupo. No Nordeste, destacam-se os trabalhos de Yamamoto (2004) e Herculano Campos (Campos \& Jucá, 2003), da Universidade Federal do Rio Grande do Norte.

Nessa mesma época, foi fundada a Associação Brasileira de Psicologia Escolar e Educacional - ABRAPEE - por psicólogos interessados em congregar os estudiosos e profissionais da área, visando, dentre outros objetivos, incentivar a melhoria da qualificação e serviços profissionais, além de estimular e divulgar pesquisas em Psicologia Escolar. Os psicólogos associados à entidade são dos mais diversos estados brasileiros.

No Maranhão, estado nordestino com um desenvolvimento ainda restrito na área da Educação e, especificamente, da Psicologia Escolar, a situação precária em que vive grande parte de sua população vem se constituindo em um apelo para que estudos, pesquisas e intervenções psicológicas comprometamse com a transformação desta realidade. A Psicologia Escolar maranhense vem aos poucos reconhecendo que tem uma contribuição importante a oferecer em relação às necessárias transformações sociais no estado. O resgate da história e das tendências atuais da Psicologia Escolar no Brasil e no Maranhão faz ver que a construção de uma formação mais consistente na área tem surgido como uma valiosa perspectiva de desenvolvimento de competências de profissionais comprometidos socialmente com o cenário educacional maranhense.

\section{Quadro atual da Psicologia Escolar no Brasil}

A Psicologia Escolar, no cenário brasileiro atual, tem fomentado inúmeros estudos, pesquisas e publicações que tem subsidiado novas práticas na área. Maluf (2003) identifica que a Psicologia Escolar brasileira está entrando em uma nova fase, "na qual se multiplicam ações afirmativas, que dão respostas a vigorosas e pertinentes críticas formuladas, sobretudo na década de 1980" (p. 137). A multiplicidade de ações a serem desenvolvidas pelo psicólogo escolar vem sendo enfatizada por diversos autores da área (Antunes, 2003; Guzzo, 1999; Martínez, 2003; Rossi \& Paixão, 2003; Senna \& Almeida, 2005; Tanamachi, 2000). As atividades e funções deste profissional diversificam-se e abrangem, cada vez mais, outros contextos educativos, além da escola. É com o passar do tempo, segundo Antunes (2003), que se poderá compreender mais ampla e nitidamente tamanha pluralidade das ações possíveis para a Psicologia Escolar contemporânea no Brasil.

As tendências atuais da Psicologia Escolar brasileira estão em consonância com o que Guzzo (1999) constatou no cenário mundial. Acompanhando discussões em âmbito internacional, a autora constata que a Psicologia 
Escolar tem sido concebida como uma especialidade que dá suporte a instituições escolares nas questões sobre o desenvolvimento humano, buscando solucionar problemas e propor estratégias de intervenção. Discutem-se modelos de atuação profissional e o preparo do psicólogo para assumir adequadamente suas funções. "O modelo de atuação passa a ser proativo, em que toda a intervenção psicológica passa a um caráter sistêmico, com focos em grupos mais do que indivíduos e atendendo à necessidade de alunos em diferentes fases do seu desenvolvimento" (Bear, Minke \& Thomas, citado por Guzzo, 1999, p. 135-136).

Há uma necessidade premente de se desenvolverem novos modelos de atuação, bem como de se dar reconhecimento às iniciativas que já surgem neste sentido, tanto por parte da sociedade quanto dos próprios profissionais psicólogos escolares. Sensível a essa realidade, Araujo (2003) desenvolveu uma pesquisa interventiva com psicólogos escolares vinculados à Secretaria de Educação do Distrito Federal, promovendo uma formação em serviço e assessoria à sua prática profissional. Como fruto deste trabalho, propôs um modelo de intervenção institucional e relacional (Araujo \& Almeida, 2003; Marinho-Araujo \& Almeida, 2005a), entendida como uma possibilidade de prevenção em Psicologia Escolar.

A intervenção institucional e relacional funda-se em ações e estratégias orientadas para que o psicólogo escolar promova a reflexão e a conscientização de funções, papéis e responsabilidades dos sujeitos que atuam no cotidiano da escola, incentive a construção de estratégias de ensino diversificadas e busque, com a equipe escolar, a superação dos obstáculos à apropriação do conhecimento pelos alunos. Trata-se de uma atuação dinâmica, participativa e sistemática na instituição, que tem as relações interpessoais como foco principal de investigação e intervenção (Araujo, 2003; Araujo \& Almeida, 2003; Marinho-Araujo \& Almeida, 2005a).

Este modelo de atuação preventiva em Psicologia Escolar atesta as profundas inovações que estão surgindo na área, sustentadas por ações críticas de psicólogos que assumem uma postura mais compromissada em seu exercício profissional. Outro exemplo significativo de um novo modelo de atuação que surgiu como contraponto às práticas acríticas em Psicologia Escolar encontra-se em Neves e Almeida (2003), que propõem que a avaliação e intervenção nas queixas escolares se desenvolvam a partir da coresponsabilização dos professores, alvos primordiais da atuação do psicólogo escolar. Superando as práticas diagnósticas e remediativas focadas no aluno, seu trabalho começaria com a escuta e orientação daquele que formula a "queixa" direcionada ao educando - o professor, abrangendo, em seguida, ações voltadas às instituições escolar e familiar para, então, chegar à abordagem ao aluno, apenas nos casos em que isso se fizer necessário. Isso se justifica pela visão mais ampla a partir da qual se entende o processo educativo atualmente, em que o sujeito da aprendizagem é compreendido como participante de uma complexa rede de relações que o constituem e que são por ele constituídas.
Os novos paradigmas que estão norteando a Psicologia Escolar brasileira contemporânea, a nova ética e o compromisso social emergente têm exigido posturas dos profissionais para as quais "nem sempre há suficiente preparo, seja no plano técnico, seja no plano pessoal" (Cruces, 2005, p. 62). Autores como Marinho-Araujo e Almeida (2005a; 2005b) e Correia e Campos (2004) afirmam que a formação inicial deficiente é um dos fatores que levam à problemática da indefinição do papel e/ou função do psicólogo escolar. Apontam, também, para fatores históricos, para a pluralidade e o paradoxo entre as tendências teóricas, para a questão do ambiente desfavorável (em termos de recursos e/ou apoio) e para o fato de o psicólogo escolar se confrontar, no contexto profissional, com outros profissionais com funções aparentemente bem definidas. Como implicações dessa problemática, os autores pontuam a dificuldade na inserção do profissional no contexto educacional e sentimentos de angústia e insegurança, gerando indefinição do campo de atuação e da identidade profissional.

Acoexistência, nos dias atuais, de modelos de atuação em Psicologia Escolar críticos e inovadores, por um lado, e práticas fundamentadas em uma visão estigmatizadora e remediativa, por outro, é uma realidade, reconhecida por Cruces (2003). Modelos de atuação restritos, curativos e acríticos, afetaram negativamente o reconhecimento desse papel profissional no Brasil, conforme análise feita por Guzzo (1999) ainda na década de 90, uma vez que, dessa forma, o psicólogo escolar não respondia satisfatoriamente à promoção do desenvolvimento dos educandos. Esta autora já defendia que a melhoria deste quadro passaria pelo investimento na formação continuada do psicólogo escolar, bem como pela crítica da prática e dos papéis que historicamente os psicólogos escolares vieram assumindo no contexto educacional.

Cantalice (2006), a partir de entrevista com a Prof. ${ }^{a}$ Dr. ${ }^{a}$ Denise Fleith, explicita a visão da referida psicóloga. Para Fleith, neste início de milênio, os profissionais que atuam em Psicologia Escolar estão, gradualmente, conscientizandose "das múltiplas tarefas que podem desenvolver, do papel inovador que podem exercer na escola, da necessidade de se trabalhar interdisciplinarmente, indo além das atribuições tradicionalmente delegadas ao psicólogo escolar" (p. 147). Daí estes profissionais virem obtendo mais visibilidade no contexto escolar.

Apesar das indefinições e dificuldades enfrentadas pelos profissionais da área, o psicólogo escolar, como pontuado por Antunes (2003), vem se comprometendo crescentemente com a superação dos problemas educacionais e buscando criar possibilidades de construção de uma educação mais democrática e efetiva. A questão ética, nessa perspectiva, passa a ser central, sendo enfrentada não apenas no âmbito da ética profissional, mas fundamentalmente de ética social.

Alinhada a essa visão, Joly (2008) convida o psicólogo escolar a uma postura crítica, política e pró-ativa, enfatizando a relevância da presença deste profissional na equipe da escola, a fim de contribuir para "potencializar 
as ações democráticas que visem à qualidade do ensino, comprometido com as necessidades e carências da sociedade brasileira" (p.11). Vê-se que, dessa forma, o psicólogo assume um papel crucial na constituição de uma cultura de sucesso escolar.

Vendo como papel do psicólogo escolar a intervenção nos processos subjetivos que promovem conscientização dos sujeitos atores do processo educacional, Guzzo (2005) afirma: "a ação do psicólogo é política, na medida em que deve influenciar mudanças em seu contexto de trabalho" ( $p$. 23). Mais do que um processo de caráter meramente abstrato, a conscientização, segundo a autora, se caracteriza por um processo de transformação pessoal e social do sujeito, na descoberta de sua realidade. "É mais do que uma mudança de opinião sobre a realidade, é a mudança na forma de se relacionar no mundo" (Guzzo, 2005, p. 27).

Ao trabalhar em prol da conscientização dos sujeitos, intervindo em processos subjetivos, o psicólogo escolar está se colocando como mediador do desenvolvimento humano nos contextos educativos, quer seja na perspectiva do desenvolvimento infantil, do adolescente ou do desenvolvimento adulto. Seu trabalho, a partir desta orientação, abrange todos os sujeitos que compartilham da subjetividade institucional, dos alunos à equipe pedagógica, à família e aos demais atores institucionais.

\section{A Psicologia Escolar no Maranhão}

\section{Caracterização do contexto maranhense}

O Maranhão é o oitavo maior estado brasileiro. Situado na Região Nordeste, faz fronteira com os estados do Piauí, Pará e Tocantins, além de ser banhado pelo Oceano Atlântico. Possui 217 municípios, dentre os quais os cinco maiores são: São Luís, Imperatriz, Timon, Caxias e Codó. São Luís, capital do Maranhão, foi fundada pelos franceses em 8 de setembro de 1612, na ilha de São Luís. O município possui 870.028 habitantes, sendo 837.584 na área urbana e 32.444 na área rural. Sua economia é baseada no comércio 6 .

Segundo dados do Programa das Nações Unidas para o Desenvolvimento levantados em $2000^{7}$, o Maranhão possui Índice de Desenvolvimento Humano (IDH) de 0,636, o pior do país, cuja média é de 0,766 . Os 27 municípios brasileiros com menor renda per capta são maranhenses e das 100 cidades com menor renda, 83 ficam no estado.

O Maranhão é o estado brasileiro que possui a menor média de escolaridade (3,6 anos), com uma taxa de analfabetismo que atinge $22 \%$ da população com mais de 10 anos de idade. A parcela empobrecida do povo, que corresponde à grande maioria dos maranhenses, tem seu percurso de educação formal atrelado ao ensino público.

6 Informações obtidas em janeiro de 2008, nos portais eletrônicos do Governo do Estado do Maranhão (http://www.ma.gov.br) e da Prefeitura de São Luís (http://www.saoluis.ma.gov.br).

7 Informações obtidas em outubro de 2008, no portal eletrônico do Programa das Nações Unidas para o Desenvolvimento - PNUD: http://pnud.org.br
Resultados preliminares do Censo Escolar $2007^{8}$ revelam que, no Maranhão, mais de $90 \%$ das matrículas efetuadas neste ano, no nível básico do ensino regular, foram em escolas da rede pública (municipais, estaduais e federais).

Tentativas têm sido feitas no sentido de reverter esse quadro. Conforme afirma Prezia (2005), organizações governamentais e não-governamentais têm se unido na promoção de ações de capacitação de secretários e conselheiros municipais, tendo em vista a elaboração de medidas que melhorem as condições socioeconômicas do Estado. Os esforços de enfrentamento, portanto, surgem de entidades sem fins lucrativos, ligadas tanto à iniciativa pública quanto privada.

Atribui-se o aprofundamento da miséria do Maranhão, nas últimas décadas, a medidas governamentais que prejudicaram os mais pobres e beneficiaram grandes grupos econômicos que, em troca, disponibilizaram seu poder aquisitivo para favorecer os que dominavam a máquina pública. Estes, dessa forma, foram gradualmente fortalecendo sua influência política no estado.

Analisando este fenômeno, Costa (2006) afirma que nas últimas décadas estabeleceu-se uma estrutura oligárquica e patrimonialista de poder no Maranhão, baseada no uso abusivo da máquina pública com vistas à ascensão, reprodução e perpetuação de grupos específicos no poder regional. Tal estrutura, segundo o autor, "é tecida por relações de poder, práticas políticas, visões de mundo, conformando uma cultura política específica" (Costa, 2006, p. 23). Essa cultura está fortemente enraizada, tendo sobrevivido a todas as mudanças experimentadas pelo Brasil ao longo do século $X X$ e se tornado um grande obstáculo à democratização do estado. Mudanças recentes no cenário político do Maranhão ainda não se mostraram suficientes para promover uma transformação neste aspecto.

\section{Breve história da Psicologia Escolar no Maranhão}

A Psicologia chegou ao Maranhão pelas mesmas vias que marcaram sua chegada a outras regiões do Brasil, apesar de bem tardiamente em comparação a estas. O estudo dos fenômenos psicológicos esteve por muito tempo atrelado às áreas médica e educacional. Enquanto profissão, a conquista de seu espaço deu-se de forma lenta, com raras oportunidades de atuação para o psicólogo.

Em sua capital, São Luís, onde surgiram os primeiros psicólogos no estado, até a década de 70 inexistiam serviços profissionais de Psicologia, conforme afirma Araújo (2005a). Foi naquela década que se iniciou uma atuação ainda restrita, com a chegada de profissionais formados em outros estados.

A maioria dos psicólogos recém-chegados atuou na área da Psicologia Organizacional, na qual havia maior demanda. Alguns atuaram na área clínica e raramente se encontravam psicólogos nas escolas (realidade observada ainda nos dias de hoje). Quando isso acontecia, segundo 8 Dados obtidos em dezembro de 2007, no portal eletrônico do Instituto Nacional de Estudos e Pesquisas Educacionais Anísio Teixeira - INEP: http://www.inep.gov.br. 
a autora, essa atuação se restringia à aplicação de testes vocacionais.

Na década de 80 , enquanto a Psicologia brasileira vivia um momento de intensas e significativas ressignificações, as questões referentes a esta ainda nem sequer faziam parte do cotidiano da maioria da população do Maranhão, uma vez que no estado existiam situações mais graves ligadas a outros problemas, como o da educação (Araújo, 2005b). Somado a isso, havia um desconhecimento generalizado acerca da atuação deste profissional.

Mesmo com a chegada de psicólogos no estado, era comum que as pessoas procurassem, em detrimento destes, o Padre João Mohana, para tratarem de assuntos de ordem psicológica, sem diferenciarem atendimento psicológico e religioso. Araújo (2005b) relata que este padre, estudioso da ciência psicológica, recebia grande reconhecimento da população por seu trabalho pautado em uma "psicologia iluminada pela fé" (p. 148).

Com o passar dos anos, a necessidade do trabalho do psicólogo no Maranhão foi lentamente se estabelecendo. Apenas na década de 90, porém, surgiram cursos de graduação em Psicologia no estado, em São Luís. No início da década, instituiu-se o curso da Universidade Federal do Maranhão - UFMA - e, no final dos anos 90, o curso do Centro Universitário do Maranhão - UNICEUMA (Araújo, 2005a). Estes dois cursos de graduação em Psicologia, o primeiro vinculado a uma instituição pública federal e o segundo a uma instituição privada, são os únicos existentes no Maranhão até a data atual. Ambos oferecem estágios em diversas áreas da Psicologia, incluindo a Psicologia Escolar. Pouco se desenvolvem, porém, atividades de pesquisa e extensão universitária nesta área, ligadas às demandas do estado, tendo em vista a falta de apoio institucional ${ }^{9}$.

A graduação em Psicologia no Maranhão vem se organizando em um momento no qual, por um lado, elaboram-se críticas e propostas de reestruturação da formação em Psicologia no âmbito nacional, e, de outro, vive-se, na Psicologia Escolar brasileira, um período de transição, marcado por uma tendência a negar os padrões tradicionais de formação e atuação na área. Observa-se que muitos profissionais formados no estado, especialmente aqueles que intencionam atuar em Psicologia Escolar e estão conscientes das sérias limitações de sua formação inicial, como a pouca ênfase dada à área no currículo e às atividades de pesquisa e extensão, inquietam-se em busca

9 Na UFMA, o estágio curricular em Psicologia Escolar é oferecido desde 1997. Entre 2002 e 2005, foi realizada, nesta universidade, a pesquisa "Gravidez na adolescência: características da educação sexual proporcionada ao aluno adolescente em escolas públicas de São Luís-MA", coordenada pelos professores do Departamento de Psicologia Maria Áurea P. Silva, Márcia Antonia P. Araújo, Paula Frassinetti Souza e Manoel William F. Gomes. Desde 2006, há um Projeto de Extensão em efetivação com os mesmos professores, intitulado "Educação sexual: envolvimento de professores e pais de alunos em um trabalho psicossocial na escola". Estas são as únicas atividades de pesquisa e extensão universitária em Psicologia Escolar das quais se tem notícia no Maranhão até a presente data. (Informações cedidas pela Profa. Ms. Maria Áurea P. Silva, em janeiro de 2007.) de oportunidades de formação continuada que possam lhes proporcionar uma maior clareza e segurança na atuação profissional.

Até outubro de 2008, o Conselho Regional de Psicologia $11^{10}$ - Seção Maranhão, havia registrado cerca de oitocentos psicólogos no estado, dentre graduados no Maranhão e em outros estados. Embora a atuação do psicólogo nas cidades do interior esteja se ampliando, mais de quinhentos profissionais encontram-se em São Luís. Não há informações consistentes acerca da área de atuação desses profissionais, uma vez que o Conselho encontra dificuldades para obter e atualizar dados desta natureza junto a estas pessoas ${ }^{11}$.

Não raras vezes, como demonstrado em pesquisa anterior (T. O. de Carvalho, 2007), ouve-se de psicólogos formados no Maranhão que sua graduação possibilitouIhes ter maior clareza acerca do que o psicólgo escolar não deve fazer, em detrimento da compreensão acerca de suas possibilidades de atuação. Para além das peculiaridades do contexto local, percebe-se que a indefinição do papel do psicólogo escolar é uma realidade nacional. Assim como acontece em outras regiões brasileiras, percebese variedade de modalidades de atuação entre os poucos psicólogos escolares do estado.

Há insuficiência de possibilidades de formação continuada na área para estes profissionais, o que pode ser constatado pela constante busca por estas possibilidades em outros estados. Pode-se perceber, também, que muitos psicólogos que desde a graduação demonstravam interesse e fizeram estágio em Psicologia Escolar acabam inserindose em formações e atuações em outras áreas, devido à falta de oportunidades no estado ou à insegurança para atuar (Carvalho, 2007).

No Maranhão, as escolas privadas, o sistema educacional público, bem como as instituições educacionais do terceiro setor (ONGs, associações etc.), têm crescentemente demandado o serviço de Psicologia Escolar, ainda que esse crescimento seja lento. A título de exemplo, tem-se que a Prefeitura de São Luís, em fevereiro de 2008, realizou concurso público para a Secretaria Municipal de Educação abrindo quatro vagas para psicólogo, sendo duas delas para psicólogo especialista em Psicopedagogia. Isso torna urgente a melhoria da formação na área, tendo em vista a necessidade de se consolidar uma Psicologia Escolar comprometida com as transformações no cenário educacional maranhense.

\section{Novas perspectivas para a Psicologia Escolar no Maranhão: A formação como instrumento de transformação}

Mudanças recentes no âmbito da formação inicial em Psicologia Escolar no Maranhão, especialmente as atreladas à UFMA, têm engendrado novas perspectivas 10 O CRP 11, cuja sede fica em Fortaleza-CE, abrange os estados Ceará, Piauí e Maranhão.

11 Dados obtidos junto a membros do Grupo Gestor do CRP 11 Seção Maranhão, do triênio 2008-2010. 
para a atuação na área. No presente artigo, centrar-se-á a análise apenas na experiência do curso de Psicologia desta Universidade.

Após passar quase dez anos tendo uma única professora efetiva em seu quadro vinculada à área da Psicologia Escolar, a Universidade realizou, em 2006, concurso público direcionado especificamente para preenchimento de uma vaga nesta área. Contudo, em razão da carência de professores efetivos no quadro, acabaram sendo contratadas mais duas docentes, também aprovadas no mesmo concurso. Houve um número significativo de candidatos vindos de outros estados para concorrer ao concurso, sendo que duas das classificações foram por parte de psicólogas maranhenses, cuja graduação foi pela própria universidade, que buscaram aprofundamento conceitual e teórico em formação acadêmica mais densa, em nível de mestrado e doutorado, no Rio de Janeiro e em Brasília. Com a entrada de mais uma professora substituta com mestrado e atuação voltados para a área, o quadro atual do Departamento de Psicologia da UFMA conta com cinco professoras na área de Psicologia Escolar.

Os frutos desta nova configuração já se fazem notar, através do fortalecimento de um grupo de docentes que, partindo de uma grande diversidade teórica, a qual só enriquece a área, têm em comum a intencionalidade de suas ações no sentido de construir uma Psicologia Escolar ancorada no compromisso com a transformação do cenário educacional maranhense. Atuando nos âmbitos do ensino, da pesquisa e da extensão, este grupo tem como perspectiva contribuir para a formação inicial e continuada de psicólogos escolares que desenvolvam ações profissionais que efetivem o relevante papel que a Psicologia tem a cumprir na interseção com a Educação no Maranhão.

No âmbito do ensino, em nível de graduação, onde as transformações têm sido mais imediatas, destaca-se o fato destes professores terem assumido as disciplinas relacionadas à área da Psicologia Escolar ${ }^{12}$, que muitas vezes foram distribuídas entre os docentes tendo como critério fundamental a disponibilidade de sua carga horária. São relevantes também as recentes reformulações no estágio curricular na área, relacionadas à ampliação das atividades realizadas devido à possibilidade de um maior acompanhamento dos estagiários por parte de duas supervisoras docentes.

\section{Psicologia Escolar e compromisso social no Maranhão: Reflexões a partir do estágio curricular da UFMA}

Estão se estruturando duas modalidades de estágio em Psicologia Escolar na UFMA, sendo uma aberta a alunos a partir do $7^{\circ}$ período e a outra a alunos do $9^{\circ}$ período em diante, sendo o critério principal para esta diferenciação as disciplinas cursadas pelos mesmos. Em ambas as modalidades desenvolve-se com os estagiários um trabalho 12 Psicologia Escolar; Psicologia da Aprendizagem; Psicologia do Desenvolvimento I, II e III; Psicopedagogia Terapêutica; Psicomotricidade. de Psicologia Escolar institucional relacional, de caráter preventivo (Marinho-Araujo \& Almeida, 2005a), pautado na intencionalidade da atuação profissional. Ao chegarem à escola que é campo do estágio, os estagiários iniciam seu trabalho realizando o Mapeamento Institucional, que os permite construir dados acerca da dinâmica institucional e refletir sobre estes, de forma a subsidiar o planejamento e implementação de ações condizentes às necessidades do contexto escolar.

O que diferencia a primeira modalidade do estágio da segunda é a ênfase, na última, para o acompanhamento do processo ensino-aprendizagem. Os estagiários desta modalidade desenvolvem um trabalho voltado à avaliação e intervenção nas queixas de aprendizagem, partindo de uma perspectiva crítico-reflexiva que supera a atuação centralizada no aluno e envolve toda a instituição escolar (Neves \& Almeida, 2003).

O estágio curricular em Psicologia Escolar está acontecendo atualmente em uma das unidades do Colégio Universitário - COLUN, escola de aplicação da UFMA. Situada em um bairro pobre de São Luís, a escola é pública, mantida com recursos da universidade, e atende alunos da $2^{a}$ à $8^{a}$ série do Ensino Fundamental. Deparando-se com uma realidade que apela à emergência de profundas transformações institucionais, os estagiários são desafiados a assumirem o caráter político que a intervenção psicológica deve possuir (Guzzo, 2005), buscando influenciar mudanças na escola.

Como constatado por Galdini e Aguiar (2003), Guzzo (2005), Patto (2005) e muitos outros autores, a situação do ensino público no Brasil é bastante precária. Apesar de garantirem um aumento do número de vagas nas últimas décadas, por não terem verdadeiramente investido na melhoria do ensino, as escolas públicas brasileiras têm mantido um discurso de inclusão bastante contraditório à exclusão verificada na realidade entre as camadas mais pobres da população, que dependem dessas instituições.

Imobilizada diante de um cotidiano promotor de um processo adaptativo e domesticado de seus educandos em relação ao mundo, esta "escola amordaçada" (Guzzo, 2005) pouco tem conseguindo fazer pelas possibilidades de transformação coletiva e individual. Tem-se defendido que a presença do estagiário, neste contexto, ao se exercitar no lugar de profissional, deve ser de procurar

Pelo diálogo, pela reflexão e pela intervenção descortinar o que consiste a vida hoje para tantos (...), descobrir formas de tornar a escola um espaço para o exercício de liberdade e autonomia, para a expressão de sentimentos e para o respeito pelo desenvolvimento daqueles que estão vivendo o processo de escolarização. (Guzzo, 2005, pp. 22-23)

Enfatiza-se, assim, a necessidade de a Psicologia Escolar contribuir para que a escola promova condições para uma transformação na ordem social, "vivendo em seu cotidiano a igualdade entre as pessoas, a convivência respeitosa, justa e a importância que cada um tem na 
formação de um coletivo" (Guzzo, 2005, p. 19). Isso implica em uma Psicologia Escolar que aceite o desafio de contribuir intencionalmente para a construção de uma educação verdadeiramente inclusiva, o que é uma necessidade premente no contexto maranhense, em que grande parcela da população encontra-se à margem de uma formação escolar de qualidade.

Segundo Martínez (2005b), o desafio essencial que o psicólogo escolar tem encontrado perante a demanda de efetivação de uma educação inclusiva se refere a esta escolha de atuar a partir de um compromisso com os menos favorecidos no processo educacional; é o querer trabalhar em prol da transformação do cenário educacional excludente e discriminatório. Segundo a autora, a competência técnica do psicólogo é secundária em relação a tal escolha, que está ligada ao seu sistema de valores, concepções de mundo, aspirações, prioridades, compromisso social com uma sociedade mais justa. Tais questões constituem-se como elementos centrais no processo de formação dos psicólogos.

Compreendendo o estágio curricular como um lócus essencial da formação inicial, tem-se buscado mediar, junto aos estagiários da UFMA, o desenvolvimento de posturas pautadas no compromisso social, sem que haja uma despreocupação com seu preparo teórico-conceitual e técnico-metodológico. Visa-se, por esta via, fomentar uma nova configuração da Psicologia Escolar no Maranhão, que contribua à transformação desse cenário educacional.

Essa perspectiva contrapõe-se ao que fora constatado por Almeida (2001). Discutindo os resultados de pesquisas brasileiras recentes em Psicologia Escolar, a autora identificou que comumente os estágios na área visam a objetivos descontextualizados da realidade sociocultural, além de não promoverem uma articulação coerente entre teoria e prática profissional. Indo na contramão desta tendência, a construção da nova Psicologia Escolar do Maranhão, que se fundamenta no aprimoramento da formação dos psicólogos, somando-se aos esforços que se tem engendrado em outros estados brasileiros, contribui para a consolidação da Psicologia Escolar crítica no cenário nacional.

\section{Considerações Finais}

O Maranhão, estado que apresenta inúmeras precariedades no que diz respeito à educação e qualidade de vida da população, requer a contribuição de psicólogos escolares que, seguros de seu papel e intencionalidade, construam uma identidade profissional comprometida com as transformações sociais da sociedade maranhense. Isso exige a melhoria da formação destes profissionais. Mudanças recentes no âmbito acadêmico maranhense têm gerado perspectivas positivas nesse sentido.

Diversas possibilidades de desenvolvimento profissional em Psicologia Escolar precisam ainda ser implementadas no estado, carente de opções de formação continuada em Psicologia. Percebe-se que a busca por aprimoramento requer muitas vezes o deslocamento dos sujeitos para outros estados que ofereçam oportunidades acadêmicas de aperfeiçoamento profissional

Urge que a UFMA, enquanto instituição de ensino superior (IES), comprometa-se tanto com o aprimoramento da formação inicial dos psicólogos como também com a formação continuada dos profissionais atuantes através de cursos de extensão e de especialização em Psicologia Escolar. Esta IES deve intensificar seus esforços para manter interlocução com outras instituições, congregando profissionais e pesquisadores de outros estados brasileiros em torno de questões referentes às atuais demandas para a formação e atuação do psicólogo escolar. É relevante, ainda, que se empenhe no desenvolvimento de pesquisas na área voltadas ao contexto maranhense, abordando tanto a atuação quanto a formação e consolidação da identidade profissional do psicólogo escolar.

Compreende-se, porém, que a construção de uma Psicologia Escolar crítica, comprometida e transformadora no Maranhão não depende exclusivamente das instituições formadoras. Percebe-se a ressonância de fatores sócioeconômicos e políticos no contexto maranhense funcionando como entraves ao ingresso e à permanência dos psicólogos escolares no mercado de trabalho. Soma-se a isso o pouco conhecimento da sociedade acerca de seu papel profissional.

Paralelamente ao já apontado, são necessárias ações de maior amplitude que envolvam a elaboração de políticas públicas que prevejam a participação do psicólogo no cenário educacional, o aumento das verbas destinadas à educação, bem como uma maior divulgação do trabalho da Psicologia Escolar junto aos maranhenses. Isso requer a mobilização da categoria profissional de psicólogos junto aos legisladores e gestores da educação no Maranhão.

Registra-se aqui, para concluir, mas não para finalizar, o descontentamento das autoras com todos aqueles que direta ou indiretamente contribuíram ou contribuem para que o Maranhão seja o estado com menor índice de desenvolvimento da nação. E seu convite à consolidação de uma Psicologia Escolar maranhense que busque a transformação desse cenário, refletindo, assim, o progresso alcançado na área em âmbito nacional nas últimas décadas. Assim como disse Joly (2007), ao se referir ao contexto brasileiro, afirmamos que, também no Maranhão, esta é a Psicologia Escolar que queremos: atuante e comprometida com o atual momento sócio-histórico e cultural.

\section{Referências}

Almeida, S. F. C. de. (2001). O psicólogo escolar e os impasses da Educação: Implicações da(s) teoria(s) na atuação profissional. Em Z. A. P. Del Prette (Org.), Psicologia Escolar e Educacional: Saúde e qualidade de vida (pp. 43-57). Campinas, SP: Alínea.

Antunes, M. A. M. (2003). Psicologia e educação no Brasil: Um olhar histórico-crítico. Em M. E. M. Meira \& M. A. M. Antunes (Orgs.), Psicologia Escolar: Teorias críticas (pp. 139-168). São Paulo: Casa do Psicólogo. 
Araujo, C. M. M. (2003). Psicologia Escolar e o Desenvolvimento de Competências: Uma Opção para a Capacitação Continuada. Tese de doutorado, Universidade de Brasília, Brasília.

Araujo, C. M. M., \& Almeida, S. F. C. de. (2003). Psicologia escolar institucional: Desenvolvendo competência para uma atuação relacional. Em S. F. C. de Almeida (Org.), Psicologia Escolar: Ética e competências na formação e atuação profissional (pp. 59-82). Campinas, SP: Alínea.

Araújo, M. A. P. (2005a). A Psicologia no Maranhão: Percursos históricos. São Luís: EDUFMA.

Araújo, M. A. P. (2005b). Conhecendo a Psicologia no Maranhão. Estudos e Pesquisas em Psicologia, 5(1), 144-157.

Bock, A. M. B. (1999). A Psicologia a caminho do novo século: Identidade profissional e compromisso social. Estudos de Psicologia, 4(2), 315-329.

Campos, H. R., \& Jucá, M. R. B. L. (2003). O psicólogo na escola: Avaliação da formação à luz das demandas do mercado. Em S. F. C. de Almeida (Org.), Psicologia Escolar: Ética e competências na formação e atuação profissional (pp. 37-56). Campinas, SP: Alínea.

Cantalice, L. M. de. (2006). Entrevista com Denise de Souza Fleith. Psicologia Escolar e Educacional, 10(1), 145-147.

Carvalho, D. B. de. (2004). A Psicologia Escolar no Brasil: uma análise da sua transformação em especialidade profissional e da sua configuração nas diretrizes curriculares. Em O. H. Yamamoto \& A. Cabral Neto (Orgs.), O Psicólogo e a Escola: Uma introdução ao estudo da Psicologia Escolar (pp. 187-203). (2a ed.). Natal: EDUFRN.

Carvalho, T. O. de. (2007). Atuação em Psicologia Escolar: O desenvolvimento de competências para a mediação da escolha profissional de adolescentes em São Luís-MA. Dissertação de Mestrado, Universidade de Brasília, Brasília.

Correia, M., \& Campos, H. R. (2004) Psicologia Escolar: histórias, tendências e possibilidades. Em O. H. Yamamoto \& A. Cabral Neto (Orgs.), O Psicólogo e a Escola: Uma introdução ao estudo da Psicologia Escolar (pp. 137-185). Natal: EDUFRN.

Costa, W. C. da. (2006). Omnia Vanitas: Uma radiografia do poder oligárquico. Em E. Azevedo, O Caso do Convento das Mercês (pp. 13-31). São Luís: Lithograf.

Cruces, A. V. V. (2003). Psicologia e educação: Nossa história e nossa realidade. Em S. F. C. de Almeida (Org.), Psicologia Escolar: Ética e competências na formação e atuação profissional (pp. 17-36). Campinas, SP: Alínea.

Cruces, A. V. V. (2005). Práticas emergentes em Psicologia Escolar: Nova ética, novos compromissos. Em A. M. Martínez (Org.), Psicologia Escolar e Compromisso Social (pp. 47-65). Campinas, SP: Alínea.

Galdini, V., \& Aguiar, W. M. J. (2003). Intervenção junto a professores da rede pública: Potencializando a produção de novos sentidos. Em M. E. M. Meira \& M. A. M. Antunes (Orgs.), Psicologia Escolar: Práticas críticas (pp. 87-103). São Paulo: Casa do Psicólogo.

Guzzo, R. S. L. (1999). Novo paradigma para a formação e atuação do psicólogo escolar no cenário educacional brasileiro. Em R. S. L. Guzzo (Org.), Psicologia Escolar: LDB e educação hoje (pp. 131-144). Campinas, SP: Alínea.

Guzzo, R. S. L. (2005). Escola amordaçada: Compromisso do psicólogo com este contexto. Em A. M. Martínez (Org.), Psicologia Escolar e Compromisso Social (pp. 17-29). Campinas, SP: Alínea.
Joly, M. C. R. A. (2007). Que Psicologia Escolar e Educacional queremos? [Editorial]. Psicologia Escolar e Educacional, 11(1), $11-12$.

Joly, M. C. R. A. (2008). Desafios da psicologia escolar e educacional [Editorial]. Psicologia Escolar e Educacional, 12(1), 11-11.

Maluf, M. R. (2003). Psicologia Escolar: Novos olhares e o desafio das práticas. Em S. F. C. de Almeida (Org.), Psicologia Escolar: Ética e competências na formação e atuação profissional (pp. 135-146). Campinas, SP: Alínea.

Marinho-Araujo, C. M., \& Almeida, S. F. C. de. (2005a). Psicologia Escolar: construção e consolidação da identidade profissional. Campinas, SP: Alínea.

Marinho-Araujo, C. M., \& Almeida, S. F. C. de (2005b). Psicologia Escolar: Recriando identidades, desenvolvendo competências. Em A. M. Martínez (Org.), Psicologia Escolar e Compromisso Social (pp. 243-259). Campinas, SP: Alínea.

Martínez, A. M. (2003). O psicólogo na construção da proposta pedagógica da escola: áreas de atuação e desafios para a formação. Em S. F. C. de Almeida (Org.), Psicologia Escolar: Ética e competências na formação e atuação profissional (pp. 105-124). Campinas, SP: Alínea.

Martínez, A. M. (2005a). Apresentação. Em A. M. Martínez (Org.), Psicologia Escolar e Compromisso Social (pp. 5-7). Campinas, SP: Alínea.

Martínez, A. M. (2005b). Inclusão Escolar: Desafios para o psicólogo. Em A. M. Martínez (Org.), Psicologia Escolar e Compromisso Social (pp. 95-114). Campinas, SP: Alínea.

Neves, M. M. B. da J., \& Almeida, S. F. C. de. (2003). A atuação da Psicologia Escolar no atendimento aos alunos encaminhados com queixas escolares. Em S. F. C. de Almeida (Org.), Psicologia Escolar: Ética e Competências na Formação e Atuação Profissional (pp. 83-103). Campinas, SP: Alínea.

Patto, M. H. S. (2005). Exercícios de Indignação: Escritos de Educação e Psicologia. São Paulo: Casa do Psicólogo.

Prezia, G. (2005). Maranhão traça plano para melhorar IDH. PNUD Brasil. Reportagens [On-line]. Recuperado: 04 ago. 2009. Disponivel: http://www.pnud.org.br.

Rossi, T. M. de F., \& Paixão, D. L. L. (2003). Significações sobre a atuação do psicólogo escolar. Em S. F. C. de Almeida (Org.), Psicologia Escolar: Ética e competências na formação e atuação profissional (pp. 147-166). Campinas, SP: Alínea.

Senna, S. R. C. M., \& Almeida, S. F. C. de. (2005). Formação e atuação do psicólogo escolar da Rede Pública de Ensino do Distrito Federal. Em A. M. Martínez (Org.), Psicologia Escolar e Compromisso Social (pp. 199-230). Campinas, SP: Alínea.

Tanamachi, E. de R. (2000). Mediações teórico-práticas de uma visão crítica em Psicologia Escolar. Em E. de R. Tanamachi, M. Proença \& M. Rocha (Orgs.), Psicologia e Educação: Desafios teórico-práticos (pp. 73-102). São Paulo: Casa do Psicólogo.

Yamamoto, O. H. (2004). A educação e a escola. Em O. H. Yamamoto \& A. Cabral Neto (Orgs.), O Psicólogo e a Escola: Uma introdução ao estudo da Psicologia Escolar (2a ed, pp. 1133). Natal: EDUFRN. 
Recebido em: $17 / 04 / 2008$

Reformulado em: 03/07/2009

Aprovado em: 16/07/2009

Sobre as autoras:

Tatiana Oliveira de Carvalho

Psicóloga da Secretaria de Estado de Educação do Maranhão, Mestre em Psicologia, Professora do Curso de Pedagogia da Unidade de Ensino Superior Dom Bosco.

Claisy Maria Marinho-Araujo

Universidade de Brasília, Doutora em Psicologia, Pesquisadora e Professora do Instituto de Psicologia e do Programa de Pós-Graduação em Desenvolvimento Humano e Saúde da Universidade de Brasília. 